\title{
Vaginal birth in singleton breech:revisited
}

\section{Hemangi K. Chaudhari*, Raviraj D. Tiruke, Parmanand K. Shah}

Department of Obstetrics and Gynecology, Seth G.S. Medical College, KEM Hospital, Mumbai, India

Received: 04 June 2016

Revised: 09 June 2016

Accepted: 13 June 2016

\section{*Correspondence:}

Dr. Hemangi K. Chaudhari,

E-mail: hemangichaudharik@gmail.com

Copyright: (C) the author(s), publisher and licensee Medip Academy. This is an open-access article distributed under the terms of the Creative Commons Attribution Non-Commercial License, which permits unrestricted non-commercial use, distribution, and reproduction in any medium, provided the original work is properly cited.

\begin{abstract}
Background: The purpose of the study was to analyze maternal and perinatal outcome according to mode of delivery in singleton breech presentation retrospectively in a tertiary care center.

Methods: This was a retrospective observational study done in KEM Hospital, during 2012 to 2013. Maternal and perinatal outcome was studied retrospectively. The data was collected from the mother's medical records. The neonatology records were also examined. Primary outcomes included neonatal mortality, morbidity and maternal morbidity.

Results: Out of 100 selected patients; 27 delivered vaginally and 73 underwent lower segment caesarean section (LSCS). Perinatal mortality was 3\%. Two out of 3 were delivered vaginally and 1 underwent LSCS. Perinatal morbidity was $1 \%$ in vaginal delivery. Maternal morbidity was $2 \%$, both patients underwent emergency LSCS. There was no maternal mortality in the study.

Conclusions: Delivery of breech fetus when labor and delivery is supervised and or conducted by experienced obstetrician lowers maternal morbidity, neonatal morbidity and mortality.
\end{abstract}

Keywords: Breech, Vaginal, LSCS

\section{INTRODUCTION}

There is lot of controversy regarding selection of candidate for trial of vaginal breech delivery. There is not enough evidence regarding the use of planned caesarean delivery for preterm babies, as well as term babies. ${ }^{1,2}$ Caesarean section has been increasingly used to deliver breech presentation to reduce neonatal mortality and morbidity. Breeches account for $10-15 \%$ of all caesarean deliveries. Breech presentation is $3^{\text {rd }}$ important indication for caesarean section in recent times.

Still caesarean section does not eliminate the risk of neonatal morbidity completely also it is associated with risks associated with anesthesia and operative complications (increased maternal morbidity). ${ }^{3}$ Some studies have shown than mode of delivery doesn't influence long term outcome even in the presence of serious short term neonatal morbidity whereas some suggest good neonatal outcome in elective lower segment caesarean section (LSCS) would definitely influence decision making regarding mode of delivery. ${ }^{4-6}$

The current study is an attempt to compare perinatal and maternal outcome between assisted breech vaginal delivery and LSCS. In short decision of delivering breech should be individualized. ${ }^{7}$

\section{METHODS}

This was a retrospective study comprising of 100 cases of breech presentation delivered after 28 week of gestation at KEM Hospital from January 2012 to November 2013. 


\section{Outcome measures studied}

Neonatal mortality, neonatal morbidity (need for NICU, fractures, paralysis, respiratory distress, AGAR score at 5 minutes,), and maternal morbidity.

\section{Inclusion criteria}

Consecutive breech deliveries 100 vaginal or abdominal occurred after 28 weeks of gestation.

\section{Exclusion criteria}

- Pregnancy with cephalic presentation.

- Infants with congenital malformations.

- Excluded footling presentation.

- IUFD, still birth.

\section{Statistical analysis}

After data collection, data entry was done in Excel. Data analysis was done with the help of SPSS Software version 15.

P-value less than 0.05 is taken as significant level.

\section{RESULTS}

As per our study, incidence of emergency LSCS was $66 \%$, elective LSCS to be $7 \%$ and that of vaginal delivery was $27 \%$. Occurrence of vaginal breech delivery was common in frank breech than complete type $(85 \% \mathrm{v} / \mathrm{s}$ $15 \%)$. This association was found to be statistically significant. Babies with birth weight between $1.5 \mathrm{~kg}$ to
$2 \mathrm{kgs}$ were found to have low Apgar scores than other groups, irrespective of mode of delivery. In multigravida patient with parity 2 or more vaginal deliveries incidence of either mode of delivery was found to be equal $(50 \%$ each), whereas in primiparous women incidence of cesarean mode delivery was higher than vaginal delivery $(72.7 \% \mathrm{v} / \mathrm{s} 27.3 \%)$.

Table 1: Distribution of study group as per, mode of delivery.

\begin{tabular}{|lll|}
\hline Mode of delivery & Frequency & Percent \\
\hline Elective LSCS & 7 & $7.00 \%$ \\
\hline Emergency LSCS & 66 & $66.00 \%$ \\
\hline Vaginal delivery & 27 & $27.00 \%$ \\
\hline Total & 100 & $100.00 \%$ \\
\hline
\end{tabular}

Table 2: Association among study group between mode of delivery and type of breech.

\begin{tabular}{|c|c|c|c|c|}
\hline \multirow{2}{*}{$\begin{array}{l}\text { Mode of } \\
\text { delivery }\end{array}$} & & \multicolumn{2}{|c|}{ Type of breech } & \multirow[t]{2}{*}{ Total } \\
\hline & & Complete & Frank & \\
\hline \multirow{2}{*}{$\begin{array}{l}\text { Elective } \\
\text { LSCS }\end{array}$} & Count & 6 & 1 & 7 \\
\hline & Percent & $85.7 \%$ & $14.3 \%$ & $100.0 \%$ \\
\hline \multirow{2}{*}{$\begin{array}{l}\text { Emergency } \\
\text { LSCS }\end{array}$} & Count & 41 & 25 & 66 \\
\hline & Percent & $62.1 \%$ & $37.9 \%$ & $100.0 \%$ \\
\hline \multirow{2}{*}{ Vaginal } & Count & 4 & 23 & 27 \\
\hline & Percent & $14.8 \%$ & $85.2 \%$ & $100.0 \%$ \\
\hline \multirow{2}{*}{ Total } & Count & 51 & 49 & 100 \\
\hline & Percent & $51.0 \%$ & $49.0 \%$ & $100.0 \%$ \\
\hline
\end{tabular}

Pearson Chi-Square value $=20.789, \mathrm{df}=2, \mathrm{p}$ value $=0.000$, There is significant association

Table 3: Association among study group between weight in grams and perinatal outcome.

\begin{tabular}{|llllll|}
\hline Weight in grams & & Perinatal outcome & Low APGAR & Died & Total \\
\hline Upto 1500 & Count & 9 & 0 & 1 & 10 \\
\hline & $\%$ & 90.0 & 0.0 & 10.0 & 100.0 \\
\hline 1501 to 2000 & Count & 7 & 2 & 0 & 9 \\
\hline & $\%$ & 77.8 & 22.2 & 0.0 & 100.0 \\
\hline 2001 to 2500 & Count & 30 & 0 & 1 & 31 \\
\hline & $\%$ & 96.8 & 0.0 & 3.2 & 100.0 \\
\hline 2501 to 3000 & Count & 35 & 0 & 0 & 35 \\
\hline & $\%$ & 100.0 & 0.0 & 0.0 & 100.0 \\
\hline 3001 to 3500 & Count & 10 & 0 & 1 & 11 \\
\hline & $\%$ & 90.9 & 0.0 & 9.1 & 100.0 \\
\hline More than 3500 & Count & 4 & 0 & 0 & 4 \\
\hline & $\%$ & 100.0 & 0.0 & 0.0 & 100.0 \\
\hline Total & Count & 95 & 2 & 3 & 100 \\
\hline & $\%$ & 95.0 & 2.0 & 3.0 & 100.0 \\
\hline
\end{tabular}

Pearson Chi-Square value $=25.101, \mathrm{df}=10, \mathrm{p}$ value $=0.005$, Significant association 
Table 4: Incidence of mode of delivery and perinatal outcome.

\begin{tabular}{|c|c|c|c|c|c|}
\hline Author & Year & $\begin{array}{l}\text { Assisted vaginal } \\
\text { breech delivery }\end{array}$ & $\begin{array}{l}\text { Perinatal mortality } \\
\text { rate }\end{array}$ & LSCS & $\begin{array}{l}\text { Perinatal mortality } \\
\text { rate }\end{array}$ \\
\hline Patwardhan et $\mathrm{al}^{16}$ & 1990 & 75.0 & 27.09 & 25.0 & 0.925 \\
\hline Present & $2012-2013$ & 27 & 7.4 & 73 & 1.3 \\
\hline
\end{tabular}

Table 5: Incidence of perinatal loss in relation to parity.

\begin{tabular}{|c|c|c|c|}
\hline Author & Year & Primigravida & Multigravida \\
\hline Fathiya $^{10}$ & 1998 & 2.4 & 1.7 \\
\hline $\begin{array}{l}\text { H. } \\
\text { Alshaheen }^{11}\end{array}$ & $\begin{array}{l}2005- \\
2006\end{array}$ & $5.7 \%$ & $2.8 \%$ \\
\hline $\begin{array}{l}\text { Present } \\
\text { study }\end{array}$ & $\begin{array}{l}2012- \\
2013\end{array}$ & 3.4 & 2.4 \\
\hline
\end{tabular}

\section{DISCUSSION}

In this retrospective study we had selected 100 cases of breech presentation delivered at KEM hospital. Hannah and colleagues published term breech trial in 2000 which showed that perinatal, neonatal mortality or serious neonatal morbidity was significantly more for planned vaginal birth group than planned caesarean section group. $^{8}$ Giuliani A et al studied outcome of 699 term singleton breech deliveries at a single center according to mode of delivery. ${ }^{9}$ It was found in their study the rate of serious perinatal morbidity in the vaginal and cesarean delivery groups was $2.3 \%$ and $0.5 \%$, respectively. There was no perinatal or neonatal death in either group. With a median follow-up period of 4 years and 9 months (range, 13-100 months), the rate of developmental delay was $1.9 \%$ and $0.5 \%$, respectively. Expected birth weight and type of breech are important parameters for outcome of breech vaginal delivery as per our study. Results in our study show that perinatal mortality was common in weight groups of less than 1500 grams and between $3 \mathrm{~kg}$ to $3.5 \mathrm{~kg}$. $22.2 \%$ of babies in weight group $1.5-2 \mathrm{~kg}$ were having low Apgar also 85\% of vaginal deliveries were in patients with frank breech.

In our study incidence of perinatal mortality in assisted breech vaginal delivery was $7.4 \%$ whereas in LSCS it was $1.3 \%$. Incidence of perinatal loss in prim gravida and multigravida was $2.4 \%$ and $1.7 \%$ respectively in study conducted by Fathiya et al in. ${ }^{10}$ Incidence of perinatal loss in study conducted by $\mathrm{H}$. Alshaheen was $5.7 \%$ and in multigravida was $2.8 \% .^{11}$ Incidence of perinatal loss was less in multigravida than primigravida $(2.4 \% \mathrm{v} / \mathrm{s} 3.4 \%)$. Increase in perinatal mortality in primigravida in assisted breech vaginal delivery may be due to rigid perineum in these patients and difficulty in delivery of after coming head. Maternal complications in the planned vaginal delivery group were fewer than in the elective caesarean section group, 2 patients of cesarean group were having abdominal wound gape in our study. Similar results were found in study by Irion $\mathrm{O}$ et al (risk difference $10.5 \%$, $95 \%$ CI 3.9 to 17.0$).{ }^{12}$ It seems that singleton term infants of multiparas do not benefit from cesarean delivery but associated with increased maternal morbidity. ${ }^{13-15}$

\section{CONCLUSION}

Is breech delivery a lost art? Is a statement similar to Is forceps a lost art?

The perinatal morbidity and mortality rate have played a huge role in changing the plan-how to deliver a breech baby. But an important fact is presence of experienced obstetrician.

Vigorous intrapartum monitoring and proper technique of breech delivery have been established as the most important determinant for successful outcome in vaginal breech delivery without compromising fetomaternal wellbeing and curtailing the caesarean section rate.

Carefully selecting women with breech presentation for vaginal delivery is a must. Our study though retrospective has fulfilled these criteria. $27 \%$ of our patients underwent assisted vaginal delivery and complications to both mother and baby were lower.

\section{Funding: No funding sources}

Conflict of interest: None declared

Ethical approval: The study was approved by the Institutional Ethics Committee

\section{REFERENCES}

1. Alfirevic Z, Milan SJ, Livio S. Caesarean section versus vaginal delivery for preterm birth in singletons. Cochrane Database Syst Rev. 2012;6:CD000078.

2. Lindqvist A, Nordén-Lindeberg $S$, Hanson U. Perinatal mortality and route of delivery in term breech presentations. $\mathrm{Br} \mathrm{J}$ Obstet Gynaecol. 1997;104(11):1288-91.

3. Hofmeyr GJ, Hannah M, Lawrie TA. Planned caesarean section for term breech delivery. Cochrane Database Syst Rev. 2015;7:CD000166.

4. Kotaska A, Menticoglou S, Gagnon R, Farine D, Basso M, Bos H, et al. Vaginal delivery of breech presentation. J Obstet Gynaecol Can. 2009;31(6):557-66,567-78. 
5. Pradhan P, Mohajer M, Deshpande S. Outcome of term breech births: 10-year experience at a district general hospital. BJOG. 2005;112(2):218-22.

6. Thorpe-Beeston JG, Banfield PJ, Saunders NJ. Outcome of breech delivery at term. BMJ. 1992;305(6856):746-7.

7. Berhan Y, Haileamlak A. The risks of planned vaginal breech delivery versus planned caesarean section for term breech birth: a meta-analysis including observational studies. BJOG. 2016;123(1):49-57.

8. Hannah ME, Hannah WJ, Hewson SA, Hodnett ED, Saigal S, Willan AR. Planned caesarean section versus planned vaginal birth for breech presentation at term: a randomized multicenter trial. Term Breech Trial Collaborative Group. Lancet. 2000;356(9239):1375-83.

9. Giuliani A, Schöll WM, Basver A, Tamussino KF. Mode of delivery and outcome of 699 term singleton breech deliveries at a single center. Am J Obstet. Gynecol. 2002187(6):1694.

10. Al-Mejhim FM, Al-Najashi SS. Trends in perinatal mortality at King Fahd Hospital of the University,
Al-Khobar, Saudi Arabia: a ten years study. J Family Community Med. 1998;5(2):31-7.

11. Alshaheen H, Abd Al-Karim A. Perinatal outcomes of singleton term breech deliveries in Basra. EMHJ. 2010;16(1):34-9.

12. Irion $\mathrm{O}$, Hirsbrunner Almagbaly $\mathrm{P}$, Morabia $\mathrm{A}$. Planned vaginal delivery versus elective caesarean section: a study of 705 singleton term breech presentations. $\mathrm{Br} \quad \mathrm{J}$ Obstet Gynaecol. 1998;105(7):710-7.

13. Obwegeser R, Ulm M, Simon M, Ploeckinger B, Gruber W. Breech infants: vaginal or cesarean delivery? Acta Obstet Gynecol Scand. 1996;75(10):912-6.

14. Kumari AS, Grundsell H. Mode of delivery for breech presentation in grand multiparous women. Int J Gynaecol Obstet. 2004;85(3):234-9.

15. Orji EO, Ajenifuja KO. Planned vaginal delivery versus caesarean section for breech presentation in Ile-Ife, Nigeria. East Afr Med J. 2003;80(11):589-91.

16. Patwardhan MV, OkaM, Mahajan N. Correlation of neonatal outcome with mode of delivery in breech presentation. Obstet Gynaecol India. 1990;40:210.

Cite this article as: Chaudhari HK, Tiruke RD, Shah PK. Vaginal birth in singleton breech:revisited. Int J Reprod Contracept Obstet Gynecol 2016;5: 2122-5. 